\title{
Effect of glycerol and corn oil on physicochemical properties of polysaccharide films - A comparative study
}

\author{
Miguel A. Cerqueira ${ }^{\mathrm{a}, *}$, Bartolomeu W.S. Souza ${ }^{\mathrm{a}, \mathrm{b}}$, José A. Teixeira ${ }^{\mathrm{a}}$, António A. Vicente ${ }^{\mathrm{a}}$ \\ ${ }^{a}$ IBB - Institute for Biotechnology and Bioengineering, Centre for Biological Engineering, University of Minho, Campus de Gualtar, $4700-035$ Braga, Portugal \\ ${ }^{\mathrm{b}}$ Departamento de Engenharia de Pesca, Universidade Federal do Ceará, Fortaleza - Ceará, Brazil
}

\section{A R T I C L E I N F O}

\section{Article history:}

Received 29 April 2011

Accepted 23 July 2011

\section{Keywords:}

Polysaccharide

Chitosan

Galactomannan

Edible films

Physicochemical properties

\begin{abstract}
A B S T R A C T
The aim of this work was to evaluate the influence of glycerol and corn oil on physicochemical properties of polysaccharide-based films. The polysaccharides used were galactomannan from Gleditsia triacanthos and chitosan. Fourier-transform infrared spectroscopy, differential scanning calorimetry and thermogravimetric analysis were performed, together with determinations of moisture content, solubility, water vapor permeability and mechanical properties. Structure-properties relationships were established, relating the two polysaccharides' structures with the way they interact with water, other film's constituents (glycerol and oil) and the resulting properties. The presence of glycerol and corn oil originated a more hydrophilic structure and a decreased affinity of the film matrix to water, respectively, in both polysaccharides. However, the two polysaccharides presented different behaviors in terms of glass transition temperature, water vapor permeability and elongation-at-break that have been related with the particularities of their structure: while for the galactomannan the specific sorption sites for water are the $\mathrm{O}-\mathrm{H}$ groups, for chitosan those are $\mathrm{O}-\mathrm{H}$ and/or $\mathrm{NH}_{2}$ groups.

The present work provides insight regarding the physicochemical properties of polysaccharide-based films and established relationships with polymers' structure, showing that the two polysaccharides studied here have adequate properties to be used as packaging materials for specific food applications. (C) 2011 Elsevier Ltd. All rights reserved.
\end{abstract}

\section{Introduction}

In the most recent years, industries have been joining efforts to reduce the amount of synthetic materials used. Therefore research on new materials from renewable resources to be used in textile, pharmaceutical, biomedical, cosmetics and food industries has progressed in order to decrease the problem of plastic waste disposal due to lack of biodegradability (Prashanth \& Tharanathan, 2007; Siracusa, Rocculi, Romani, \& Rosa, 2008). In this context edible films based on polysaccharides and/or proteins appear as potential substitutes of synthetic packaging, thus playing a decisive role in the improvement of the shelf-life of food through controlling gas transfer and being carriers of functional compounds (Srinivasa, Ramesh, \& Tharanathan, 2007).

Polysaccharides are natural polymers composed of monosaccharide residues that are connected by O-glycosidic linkages and, depending on their source, they can be neutral, positively or negatively charged. They either act as energy reserve in plants and animals, or have structural roles in plant cell walls or in the tough

\footnotetext{
* Corresponding author. Tel.: +351 253604 400; fax: +351 253604429 .

E-mail address: miguelcerqueira@deb.uminho.pt (M.A. Cerqueira).
}

outer skeleton of insects and other animals (Nelson \& Cox, 2000). The great diversity of structural features of polysaccharides have origin from differences in the monosaccharide composition, linkage types and patterns, chain shapes, and degree of polymerization, influencing their physicochemical properties.

Galactomannans are present in the endosperm of numerous plants, and they have several functions, e.g. as a reserve of carbohydrates. Galactomannans are polysaccharides built up of a $\beta$ (1-4)-D-mannan backbone with single D-galactose branches linked $\alpha-(1-6)$ (Kök, Hill, \& Mitchell, 1999). Galactomannans can often be used in different forms for human consumption. Featuring different physicochemical properties, galactomannans are a versatile material used for many applications: they are excellent stiffeners and stabilizers of emulsions, and the absence of toxicity allows their use in the textile, pharmaceutical, biomedical, cosmetics and food industries (Srivastava \& Kapoor, 2005). Gleditsia triacanthos belongs to the family Leguminosae and grows in America, Middle Europe and Mediterranean area (Üner \& Altınkurt, 2004). Seeds of G. triacanthos were used as source of the galactomannan used as raw material for edible films production.

Chitosan is a natural polymer derived by deacetylation of chitin, the second most abundant biopolymer in nature after cellulose 
(Shahidi, Arachchi, \& Jeon, 1999). When compared with other polysaccharides, chitosan has several important advantages such as biocompatibility, biodegradability and no toxicity; several studies indicated chitosan as bacteriostatic and fungistatic (Yi et al., 2005). The polycationic properties of chitosan provide the possibility of film formation by the breakage of polymer segments and subsequent reforming of the polymer chain into a film matrix or gel; this can be achieved through the evaporation of the solvent thus creating hydrophilic and hydrogen bonding and/or electrolytic and ionic crosslinking.

Natural biopolymers present several advantages over synthetic polymers but their application is limited by their high affinity to water, leading to textural transformations that have a strong impact on their mechanical, transport and solubility properties. In a previous publication the development of edible films based in chitosan and galactomannan was discussed (Cerqueira, Lima, et al., 2009), however no relationship was established between their structure and their properties. To our knowledge no work has been published comparing the physicochemical properties of these two polysaccharides and very few publications do it for other polysaccharides. Further, the understanding of their structure-properties relationship in order to predict and control their function is one of the major flaws in this area, especially when mixtures with other substances are considered (which is often the case). In fact, the incorporation of other compounds, such as plasticizers and lipids, is common in order to improve mechanical and transport properties of edible films (Bergo \& Sobral, 2007), but research focused on e.g. polysaccharides' interaction with other film components is needed in order to understand the influence of such components in films' properties.

Plasticizers are commonly used to facilitate processing and/or to increase films flexibility. Water, oligosaccharides, polyols, and lipids are different types of plasticizers widely used in hydrocolloid-based films (Suyatma, Tighzert, Copinet, \& Coma, 2005). Their combination could give rise to synergistic effects between components improving the properties of edible films. The lubrication theory postulates that plasticizers, by interspersing themselves, act as internal lubricants by reducing frictional forces between polymer chains. The gel theory postulates that the rigidity of the polymer network comes from its threedimensional structure, and plasticizers take effect by breaking polymer-polymer interactions (e.g., hydrogen bonds and van der Waals or ionic forces). The free volume theory states plasticization as a way to increase free volume (Santosa \& Padua, 1999; Suyatma et al., 2005). Glycerol is a major by-product of biodiesel production which has significantly increased, thus creating a significant surplus and is often regarded as a waste stream with an associated cost (Fountoulakis \& Manios, 2009; Gu \& Jérôme, 2010). The use of glycerol as plasticizer in these films can be a way to help solving the existing surplus of this co-product from biodiesel production. Lipids, due their hydrophobic behavior, are added to polysaccharide films aiming at decreasing their hydrophilicity, consequently decreasing their water affinity (Vargas, Albors, Chiralt, \& González-Martínez, 2009). From all the commercial oils, corn oil has shown to be one of the most effective, in comparison with others, in decreasing the water vapor permeability of polysaccharide and protein films (Ekthamasut \& Akesowan, 2001; Tanaka, Ishizaki, Suzuki, \& Takai, 2001).

The aim of this study was to evaluate the influence of glycerol and corn oil presence in the properties of the films. This was achieved by relating the information gathered from Fourier-transform infrared spectroscopy, thermal analyses (DSC and TGA), solubility measurements, moisture content determinations, water vapor permeability measurements and mechanical tests.

\section{Materials and methods}

\subsection{Films preparation}

Chitosan film-forming solutions were prepared dissolving chitosan (deacetylation degree of $90 \%$ approximately, Aqua Premier Co., Thailand) $(1.5 \% \mathrm{w} / \mathrm{v})$ in a lactic acid $(1.0 \% \mathrm{v} / \mathrm{v})$ solution (Merck, Germany) with agitation using a magnetic stirrer (at $200 \mathrm{rpm}$ ) overnight at room temperature $\left(20^{\circ} \mathrm{C}\right)$; Tween 80 (0.2\%) (Acros Organics, Belgium) was also added as surfactant. Galactomannan film-forming solutions were prepared by dissolving G. triacanthos galactomannan (obtained as described in Cerqueira, Pinheiro, et al. (2009)) $(1.5 \% \mathrm{w} / \mathrm{v})$ in distilled water, followed by the same conditions as for chitosan. Glycerol (87\%, Panreac, Spain) was added at three different concentrations $(0.5,1.25$ and $2.0 \% \mathrm{w} / \mathrm{v})$. Corn oil (Sovena, Portugal) was added at three different concentrations $(0.25,0.5$ and $0.75 \% \mathrm{w} / \mathrm{v})$ under agitation during $20 \mathrm{~min}$ at $60^{\circ} \mathrm{C}$, to films with constant concentrations of $1.5 \%$ of polysaccharide and $0.5 \%$ of glycerol. To produce the films, a constant amount $(13 \mathrm{~mL})$ of film-forming solution was cast onto a $5.7 \mathrm{~cm}$ diameter Petri plate. The films were dried in an oven at $35^{\circ} \mathrm{C}$ during $16 \mathrm{~h}$. Films were maintained at $23^{\circ} \mathrm{C}$ and $54 \% \mathrm{RH}$ at least $24 \mathrm{~h}$ before performing the tests (these conditions were obtained in a desiccator through a saturated salt solution of $\left.\mathrm{Mg}\left(\mathrm{NO}_{3}\right)_{2}\right)$.

\subsection{Moisture content}

To determine the moisture content of films about $50 \mathrm{mg}$ of film were dried at $105{ }^{\circ} \mathrm{C}$ during $24 \mathrm{~h}$ (until the equilibrium weight was attained). The weight loss of the sample was determined, from which the moisture content was calculated using the following equation:

Moisture content $=\frac{\left(M_{\mathrm{i}}-M_{\mathrm{f}}\right)}{M_{\mathrm{i}}} \times 100$

where $M_{\mathrm{i}}$ and $M_{\mathrm{f}}$ are the masses of initial and dried samples, respectively.

\subsection{Fourier-transform infrared (FTIR) spectroscopy}

The IR spectra of the films were determined using an infrared spectrometer (FTIR) (Perkin-Elmer 16 PC spectrometer, Boston, USA), in Attenuated Total Reflectance mode (ATR) between 400 and $4000 \mathrm{~cm}^{-1}$, using 16 scans at a resolution of $4 \mathrm{~cm}^{-1}$. Before film analysis, an open bean background spectrum of clean crystal was recorded. Data analysis of each film was performed with Peak Fit 4.12 (SYSTAT Software Inc., Richmond, CA, USA) program. Spectra of films have been deconvoluted with the second derivative method with a smoothing filter set at $15 \%$.

\subsection{Differential scanning calorimetry (DSC) and thermogravimetric analysis (TGA)}

Differential scanning calorimetry (DSC) measurements were performed with a Shimadzu DSC-50 (Shimadzu Corporation, Kyoto, Japan) calibrated with Indium as standard. Ca. $10 \mathrm{mg}$ of the sample was placed in aluminum DSC pans (Al crimp Pan C.201-52943). The measurements were performed between -100 and $250{ }^{\circ} \mathrm{C}$ at a heating rate of $10^{\circ} \mathrm{C} \mathrm{min}^{-1}$ under a nitrogen atmosphere. In a first heating scan the enthalpy of melting $\left(\Delta H_{\mathrm{m}}\right)$ and the melting peak $\left(T_{\mathrm{m}}\right)$ were determined; a second heating allowed the measurement of glass transition temperature $\left(T_{\mathrm{g}}\right)$. Thermogravimetric analysis (TGA) was completed with a Shimadzu TGA-50 (Shimadzu Corporation, 
Kyoto, Japan). Samples were placed in the balance system and heated from $20^{\circ} \mathrm{C}$ to $580^{\circ} \mathrm{C}$ at a heating rate of $10^{\circ} \mathrm{C} \mathrm{min}^{-1}$ under a nitrogen atmosphere.

\subsection{Water solubility}

The films' solubility in water was determined according to the method reported by Cuq, Gontard, Cuq, and Guilber (1996). Solubility is defined as the content of dry matter solubilized after $24 \mathrm{~h}$ immersion in water. The initial dry matter content of each film was determined by drying to constant weight in an oven at $105^{\circ} \mathrm{C}$. Disks of film ( $2 \mathrm{~cm}$ diameter) were cut, weighed $\left(M_{\mathrm{i}}\right)$, and immersed in $50 \mathrm{~mL}$ of water. After $24 \mathrm{~h}$ of immersion at $20^{\circ} \mathrm{C}$ with agitation (60 rpm), the pieces of film were taken out and dried to constant weight $\left(M_{\mathrm{f}}\right)$ in an oven at $105^{\circ} \mathrm{C}$, to determine the weight of dry matter that was not solubilized in water. The solubility of the films was then determined as follows:

Water solubility $=\frac{\left(M_{\mathrm{i}}-M_{\mathrm{f}}\right)}{M_{\mathrm{i}}} \times 100$

where $M_{\mathrm{i}}$ is the initial mass and $M_{\mathrm{f}}$ is the final mass of the sample.

\subsection{Film thickness}

The film thickness was measured with a digital micrometer (No. 293-561, Mitutoyo, Japan). Five thickness measurements were taken on each testing sample in different points and the mean values were used to calculate permeability and mechanical properties.

\subsection{Water vapor permeability (WVP) measurement}

The measurement of water vapor permeability (WVP) was performed gravimetrically based on ASTM E96-92 method (Guillard, Broyart, Bonazzi, Guilbert, \& Gontard, 2003; McHugh, Avena-Bustillos, \& Krochta, 1993). The film was sealed on the top of a permeation cell containing distilled water (100\% RH; $2337 \mathrm{~Pa}$ vapor pressure at $20^{\circ} \mathrm{C}$ ), placed in a desiccator at $20^{\circ} \mathrm{C}$ and $0 \% \mathrm{RH}$ ( $0 \mathrm{~Pa}$ water vapor pressure) containing silica. The cells were weighted at $2 \mathrm{~h}$ intervals during $10 \mathrm{~h}$. Steady-state and uniform water pressure conditions were assumed by keeping the air circulation constant outside the test cell by using a miniature fan inside the desiccator (Guillard et al., 2003). The slope of weight loss versus time was obtained by linear regression. The measured (WVP) of the films was determined as follows:

$\mathrm{WVP}=\frac{\mathrm{WVTR} \cdot L}{\Delta P}$

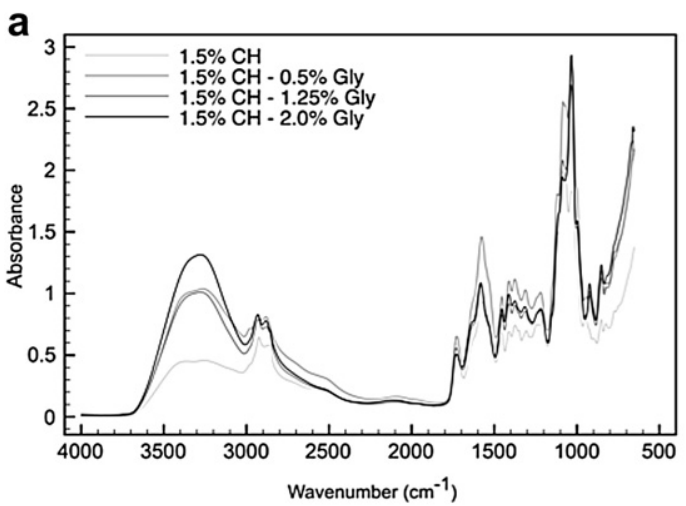

where WVTR is the measured water vapor transmission rate through a film, $L$ is the mean film thickness ( $\mathrm{m})$, and $\Delta P$ is the partial water vapor pressure difference $(\mathrm{Pa})$ across the two sides of the film. Three replicates were obtained for each film.

\subsection{Tensile strength (TS) and elongation-at-break (EB)}

TS and EB were measured with an Instron Universal Testing Machine (Model 4500, Instron Corporation) following the guidelines of ASTM Standard Method D 882-91 (ASTM-D-882-91, 1991). The initial grip separation was set at $30 \mathrm{~mm}$ and the crosshead speed was set at $5 \mathrm{~mm} \mathrm{~min}^{-1}$. TS was expressed in Pa and calculated by dividing the maximum load $(\mathrm{N})$ by the initial crosssectional area $\left(\mathrm{m}^{2}\right)$ of the specimen. EB was calculated as the ratio of the final length at the point of sample rupture to the initial length of a specimen $(30 \mathrm{~mm})$ and expressed as a percentage. According to the ASTM standard, film strips with a length of $45 \mathrm{~mm}$ and a width of $20 \mathrm{~mm}$ were used. TS and EB tests were replicated at least three times for each type of film.

\subsection{Statistical analyses}

Statistical analyses were performed using Analysis of Variance (ANOVA) and linear regression analysis. The Tukey test $(\alpha=0.05)$ was used to determine any significance of differences between specific means (SigmaStat, trial version, 2003, USA).

\section{Results and discussion}

\subsection{Fourier-transform infrared (FTIR) spectroscopy}

The effect of glycerol and oil in chitosan and galactomannan films was initially evaluated by FTIR analyses. Fig. 1a shows the FTIR spectra of the chitosan $(\mathrm{CH})$ films containing $0,0.5,1.25$ and $2.0 \%$ of glycerol (Gly). The broad band ranging between 3500 and $3100 \mathrm{~cm}^{-1}$ is attributed to $\mathrm{O}-\mathrm{H}$ stretching vibration that overlaps the $\mathrm{N}-\mathrm{H}$ stretching vibration in the same region. The broad band between 2800 and $3000 \mathrm{~cm}^{-1}$ is attributed to $\mathrm{C}-\mathrm{H}$ stretching vibration. The peak at $1574 \mathrm{~cm}^{-1}$ was due to the $\mathrm{N}-\mathrm{H}$ beading (amide II); and the peak at $1733 \mathrm{~cm}^{-1}$ suggests the presence of a carbonyl group $(\mathrm{C}=\mathrm{O})$ in the film matrix (Xu, Kim, Hanna, \& Nag, 2005; Ziani, Oses, Coma, \& Maté, 2008). When compounds are mixed, physical bonds and chemical interactions are reflected by changes in characteristic spectra peaks. By deconvolution of the area band between 800 and $1200 \mathrm{~cm}^{-1}$ of FTIR spectra seven bands appear. Peak positions and areas of bands between 800 and $1200 \mathrm{~cm}^{-1}$ for chitosan films with increasing glycerol concentrations after the application of deconvolution are presented in Table 1

b

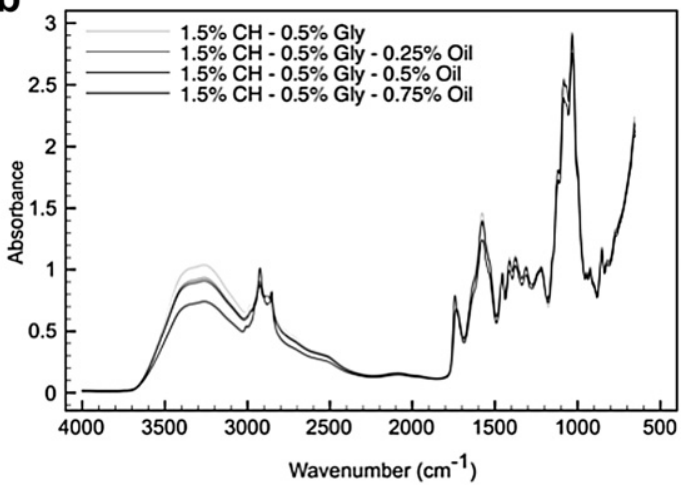

Fig. 1. FTIR spectra of chitosan films for increasing glycerol (a) and oil (b) concentrations. 
of the Supplementary data. Glycerol incorporation leads to a shift of the peak $942.9 \mathrm{~cm}^{-1}$, presented in chitosan films without glycerol, to peak + bands of $929.2,923.1$ and $920.5 \mathrm{~cm}^{-1}$ for chitosan films with $0.5,1.25$ and $2.0 \%$ of glycerol, respectively. This shift can be related with the symmetric stretching vibrations of the alcoxyl group $(\mathrm{C}-\mathrm{O}-\mathrm{C})$, resulting of the glycerol presence (Jamróz et al., 2007). Also the shift of the peak $999.9 \mathrm{~cm}^{-1}$, of the chitosan films without glycerol, to $994.1,991.2$ and $990.2 \mathrm{~cm}^{-1}$ for chitosan films with $0.5,1.25$ and $2.0 \%$ of glycerol, respectively, can be related with the asymmetric stretching vibrations of the alcoxyl group $(\mathrm{C}-\mathrm{O}-\mathrm{C})$ (Jamróz et al., 2007). Moreover, the broad band that corresponds to the $\mathrm{O}-\mathrm{H}$ stretching vibration $\left(3500-3100 \mathrm{~cm}^{-1}\right.$ ) was more intense for higher glycerol concentrations. Table 2 of the Supplementary data shows the peaks + areas of bands after the application of deconvolution of the FTIR spectra to the area band between 2500 and $3500 \mathrm{~cm}^{-1}$ for chitosan films with increasing glycerol concentrations. The increase of glycerol concentrations leads to a higher number of bands after the deconvolution of the spectra. For chitosan films with $2.0 \%$ of glycerol the deconvolution origins two more peaks when compared with the other chitosan films; furthermore the area of the bands between 3500 and $3100 \mathrm{~cm}^{-1}$ increased with the increasing of glycerol concentrations, confirming the higher intensity of $\mathrm{O}-\mathrm{H}$ bonds. Also evident is the decrease of the area of the bands close to those at ca. $2720 \mathrm{~cm}^{-1}$ and ca. $2900 \mathrm{~cm}^{-1}$ that correspond to the $\mathrm{C}-\mathrm{H}$ stretching vibration. The increase of glycerol concentration leads to higher numbers of $\mathrm{O}-\mathrm{H}$ bonds and consequently higher band areas, also resulting in the decrease of the areas that correspond to the $\mathrm{C}-\mathrm{H}$ bonds (Table 2 of the Supplementary data).

Fig. 1b shows FTIR spectra of chitosan films for increasing oil concentrations. FTIR spectra of chitosan films with oil also show a high and more intense number of peaks in the frequency range between 2800 and $3100 \mathrm{~cm}^{-1}$. By the deconvolution of FTIR band ranging between 2500 and $3500 \mathrm{~cm}^{-1}$ a different number of peaks appear for chitosan films without and with oil. These results are presented in Table 3 in the Supplementary data, where two new peaks appear when oil is added to chitosan films. The most relevant peak, ca. $2925 \mathrm{~cm}^{-1}$, can be related with the symmetric and asymmetric stretching vibration of the aliphatic group $\left(\mathrm{CH}_{2}\right)$ (Vlachos et al., 2006), with a more intense area (27\%) for chitosan films with $0.75 \%$ of oil. Table 4 in the Supplementary data presents the results for the deconvolution of the FTIR area band ranging between 1600 and $1800 \mathrm{~cm}^{-1}$; it shows that the oil incorporation leads to the presence of a new band at ca. $1740 \mathrm{~cm}^{-1}$, that is only observed for chitosan films when oil is added. Table 4 in the Supplementary data also shows an increase of the area from 30.2 to 31.0 and $40.9 \%$ for $0.25,0.5$ and $075 \%$ of oil, for the band ca.
$1740 \mathrm{~cm}^{-1}$. This peak corresponds to the $\mathrm{C}=\mathrm{O}$ stretching vibration, that can be explained by the presence of the carbonyl radical in the ester functional group of the triglycerides, associated with the presence of corn oil, at $1746 \mathrm{~cm}^{-1}$ (Vlachos et al., 2006).

Fig. 2a and b shows FTIR spectra of galactomannan films for increasing glycerol and oil concentrations, respectively. The broad band ranging between 3500 and $3100 \mathrm{~cm}^{-1}$ is attributed to $\mathrm{O}-\mathrm{H}$ stretching vibration formed by the hydroxyl group of galactomannan and water and the broad band around $2800-3000 \mathrm{~cm}^{-1}$ is attributed to $\mathrm{C}-\mathrm{H}$ stretching vibration (Yuen, Choi, Phillips, \& Ma, 2009). Table 5 in the Supplementary data shows the peak + areas of bands between 2500 and $3500 \mathrm{~cm}^{-1}$ for galactomannan films with increasing glycerol concentrations, after the deconvolution of FTIR spectra. The increasing glycerol concentration increases the FTIR spectra area corresponding to the region of the $\mathrm{O}-\mathrm{H}$ stretching vibration $\left(3500-3100 \mathrm{~cm}^{-1}\right)$, decreasing the number of bands/peaks from eight to four. This phenomenon is related with the hydrophilic behavior of glycerol and due to the hydrogen bonds formed by the hydroxyl groups of both galactomannan and glycerol structures. The presence of glycerol also leads to changes in the band region ranging between 800 and $1200 \mathrm{~cm}^{-1}$, which is giving information about the alcoholic $(\mathrm{C}-\mathrm{O})$ stretching bands and the asymmetric and symmetric (C-O-C) stretching vibrations bands (Jamróz et al., 2007). Table 6 in the Supplementary data shows the peaks + areas of bands between 800 and $1200 \mathrm{~cm}^{-1}$ for galactomannan films with increasing glycerol concentrations, after the application of deconvolution process. The band with the peak at $1078.7 \mathrm{~cm}^{-1}$ shifts to $1083.2,1094.8$ and $1089.2 \mathrm{~cm}^{-1}$ for chitosan films with glycerol, that can result from the stretching vibration of $\mathrm{C}-\mathrm{O}$ in $\mathrm{C}-\mathrm{O}-\mathrm{H}$ bonds. The broad band at $1017.2 \mathrm{~cm}^{-1}$ that corresponds to the stretching vibration of $\mathrm{C}-\mathrm{O}$ in $\mathrm{C}-\mathrm{O}-\mathrm{C}$ bonds appears in all galactomannan film samples, however presenting a shift to $1022.8,1034.7$ and $1030.5 \mathrm{~cm}^{-1}$ for galactomannan films with $0.5,1.25$ and $2.0 \%$ of glycerol, respectively. Moreover, the broad band at ca. $920 \mathrm{~cm}^{-1}$ that also corresponds to the stretching vibration of $\mathrm{C}-\mathrm{O}$ in $\mathrm{C}-\mathrm{O}-\mathrm{C}$ bond, only appears in the films containing glycerol, confirming the more intense $\mathrm{C}-\mathrm{O}$ stretching vibration in these films' structure (Jamróz et al., 2007; Pelissari, Grossmann, Yamashita, \& Pineda, 2009).

Also changes in the frequency range between 2800 and $3500 \mathrm{~cm}^{-1}$ are observed when oil is added to galactomannan films. Table 7 in Supplementary data shows the shift of the band at $2905.5 \mathrm{~cm}^{-1}$ to a peak + band of ca. $2850 \mathrm{~cm}^{-1}$ when oil is added. Also a new peak + band at ca. $2925 \mathrm{~cm}^{-1}$ appears in the FTIR spectra of galactomannan films with oil. These two peaks + bands are related with symmetric and asymmetric stretching vibration of the aliphatic $\mathrm{C}-\mathrm{H}$ group $\left(\mathrm{CH}_{2}\right)$ (Vlachos et al., 2006). By other side, the broad band ranged between 3500 and $3100 \mathrm{~cm}^{-1}$, associated to
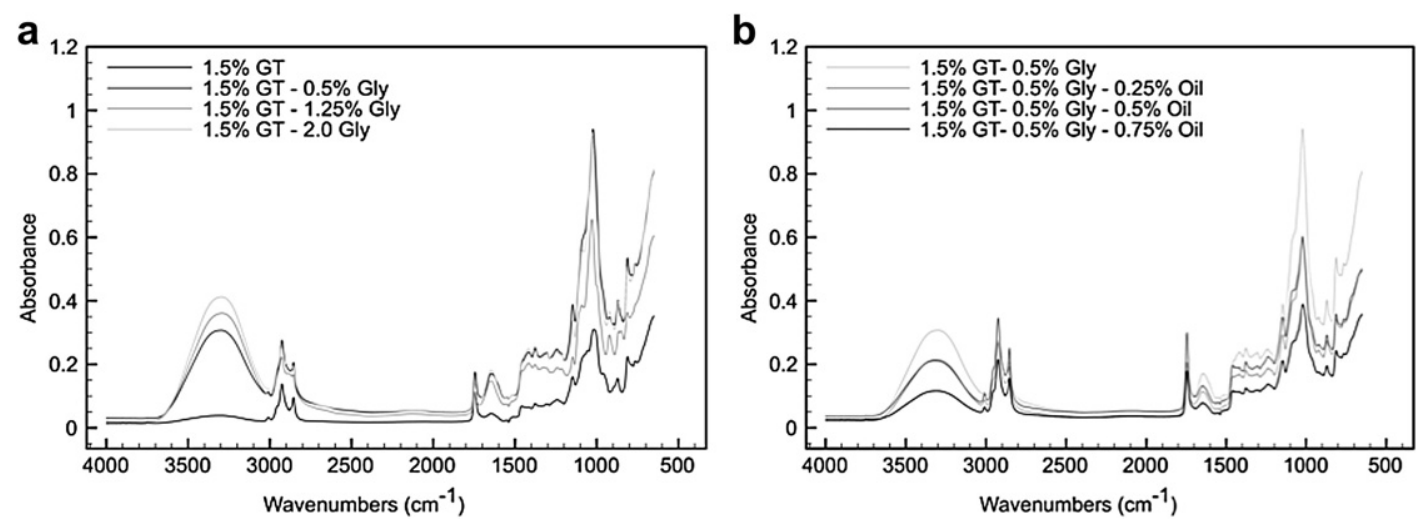

Fig. 2. FTIR spectra of the galactomannan (GT) films for increasing glycerol (Gly) (a) and oil (b) concentrations. 
the $\mathrm{O}-\mathrm{H}$ stretching vibration, shows a lower intensity that can be associated with hydroxyl bonds of the films that decrease when oil is added to the film (Yuen et al., 2009), leading to a more hydrophobic matrix. Also in the area band between 1600 and $1800 \mathrm{~cm}^{-1}$ changes were observed in the FTIR spectra for galactomannan films with increasing oil concentrations. By the application of deconvolution to this area band six peaks appear, decreasing for five peaks for a concentration of $0.75 \%$ of oil (Table 8 in the Supplementary data). With the increasing of oil concentration it is evident the increase of the area of the peak + band around $1744 \mathrm{~cm}^{-1}$, associated with the carbonyl radical in the ester functional group of triglycerides (Vlachos et al., 2006).

\subsection{Moisture content and thermal analyses}

The determination of moisture content gives information on the amount of water present in the films, while the differential scanning calorimetry (DSC) analyses were used to measure the glass transition temperature $\left(T_{\mathrm{g}}\right)$, the enthalpy of melting $\left(\Delta H_{\mathrm{m}}\right)$ and the peak melting temperature $\left(T_{\mathrm{m}}\right)$ of the films. $T_{\mathrm{g}}$ is a parameter associated with the system mobility, and is defined as a physical change from the glassy to the rubbery state in amorphous materials promoted by heat (Roos \& Karel, 1991), while $\Delta H_{\mathrm{m}}$ and $T_{\mathrm{m}}$ can be associated with the crystallinity of the films samples.

Fig. 3a and b shows the variations of the moisture content in chitosan films for increasing concentrations of glycerol and oil, respectively. The presence of water in chitosan films is highly dependent on glycerol concentration. Glycerol, due to its hydrophilic nature, retains water in the film matrix. Higher concentrations of plasticizer favor the adsorption of water molecules, which is mainly attributed to the predisposition of plasticizers to form hydrogen bonds $(\mathrm{O}-\mathrm{H})$, confirmed by FTIR spectra analyses. On the other hand, it is observed that moisture content decreases for films with oil (Fig. 3b) when compared with films without oil. However, the values do not present a statistically significant difference $(p>0.05)$ between chitosan films with different oil concentrations.

Fig. $4 \mathrm{a}$ and $\mathrm{b}$ shows the variations of the moisture content in galactomannan films for increasing concentrations of glycerol and oil, respectively, and presents a similar behavior to chitosan films. Water is not only associated with the galactomannan film's structure, but also with the glycerol hydrophilic nature that retains water in the matrix. Furthermore, a decrease in the water content is observed for galactomannan films with oil, (Fig. 4b), in agreement with FTIR spectra analyses.

Fig. 3a shows $T_{\mathrm{g}}$ values for chitosan films with different glycerol concentrations. Glycerol, due its plasticizing effect, decreases glass transition temperatures of polysaccharide films, which is in agreement with the free volume theory of plasticization. The increase of glycerol concentration leads to an increase of the free volume and mobility of molecules, changing the physical structure of the chitosan film, which is in agreement with the decrease of the $T_{\mathrm{g}}$ values. Moreover, $T_{\mathrm{g}}$ values are inversely associated with the moisture content of chitosan films; in fact, also water acts as a plasticizer increasing the molecular mobility (lower $T_{\mathrm{g}}$ values) of the chitosan films. Glycerol changes the polymer network creating mobile regions with greater interchain distances, promoting water clustering (Diab, Biliaderis, Gerasopoulos, \& Sfakiotakis, 2001; Olivas \& Barbosa-Cánovas, 2008), thus increasing the moisture content in the films. The thermograms present a great decrease of $T_{\mathrm{g}}$ values for glycerol concentrations of $2.0 \%$, that can be explained by the value reported for the $T_{\mathrm{g}}$ of glycerol $\left(-75^{\circ} \mathrm{C}\right.$ ) (Mathew \& Dufresne, 2002). $T_{\mathrm{g}}$ values obtained here are in agreement with those reported in other works (Dong, Ruan, Wang, Zhao, \& Bi, 2004; Suyatma et al., 2005). Oil incorporation in chitosan films decreases the mobility of the chitosan matrix, as confirmed by the increase $(p<0.05)$ of $T_{g}$ values (Fig. 3b). However, the increase of oil concentrations does not lead to statistically significant differences $(p>0.05)$ between $T_{\mathrm{g}}$ values. This behavior is in agreement with the moisture content of the films containing oil, that also does not present a statistically significant difference $(p>0.05)$ for different oil concentrations.

Fig. 4a shows $T_{\mathrm{g}}$ of galactomannan films for different glycerol concentrations. Results show that the presence of glycerol decreases $(p<0.05)$ the values of $T_{\mathrm{g}}$. Higher glycerol concentrations lead to the increase of the free volume of the polymer matrix and consequently to the increase of the mobility of molecules, thus changing the physical structure of the film and decreasing $T_{\mathrm{g}}$ (Roos \& Karel, 1991). Moreover, $T_{\mathrm{g}}$ values are inversely associated with the water content of the galactomannan films; also, water itself acts as a plasticizer increasing the molecular mobility (lower $T_{\mathrm{g}}$ values) in the galactomannan films. The presence of glycerol contributes to the establishment of more hydrogen bonds in the film matrix, as confirmed by FTIR analyses. The $T_{\mathrm{g}}$ values obtained for galactomannan films are in agreement with reported results for galactomannan films from other sources (Mikkonen et al., 2007). Oil incorporation decreases the mobility of the galactomannan matrix (increase of $T_{\mathrm{g}}$ values) that can be related with the oil structure (e.g. aliphatic $\mathrm{C}-\mathrm{H}$ group and carbonyl radical in the ester functional group) and also with the decrease of the moisture content of films (Fig. 4b).

Fig. $5 \mathrm{a}$ and b shows the changes of $\Delta H_{\mathrm{m}}$ and $T_{\mathrm{m}}$ of chitosan and galactomannan films, respectively, with the increase of glycerol concentration. For chitosan films the increase of glycerol concentration leads to an increase of $\Delta H_{\mathrm{m}}$, and to a decrease of $T_{\mathrm{m}}$ values. The higher values of $\Delta H_{\mathrm{m}}$ are possibly explained by the increase of the crystallinity of chitosan films (Sperling, 2006). When glycerol concentration increases, a greater polymer mobility (lower $T_{\mathrm{g}}$ values) is obtained that favors the formation of crystalline domains
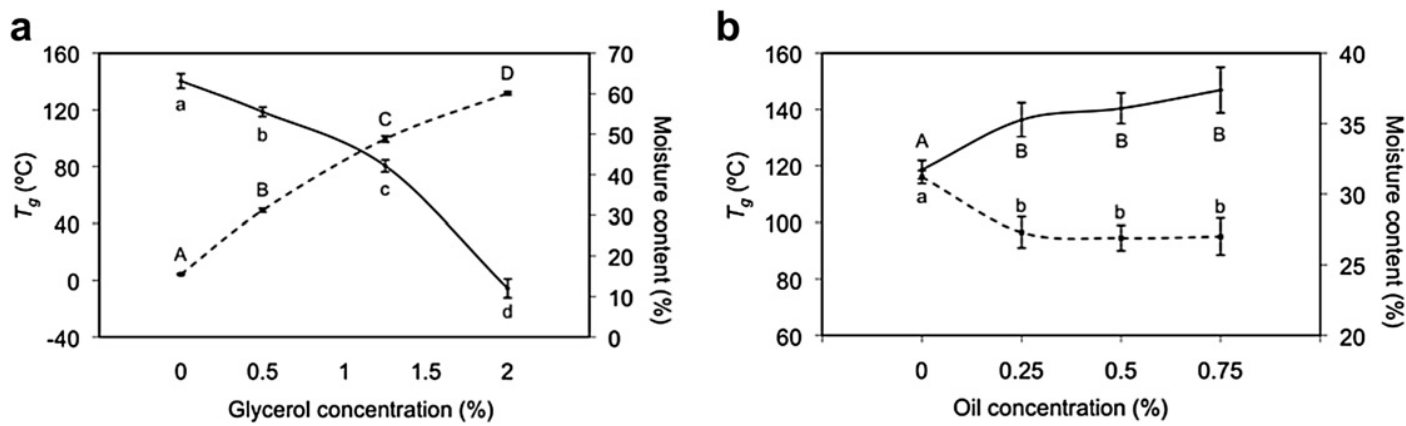

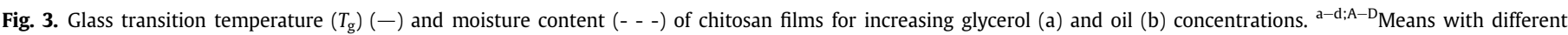
superscripts are significantly different $(p<0.05)$. 

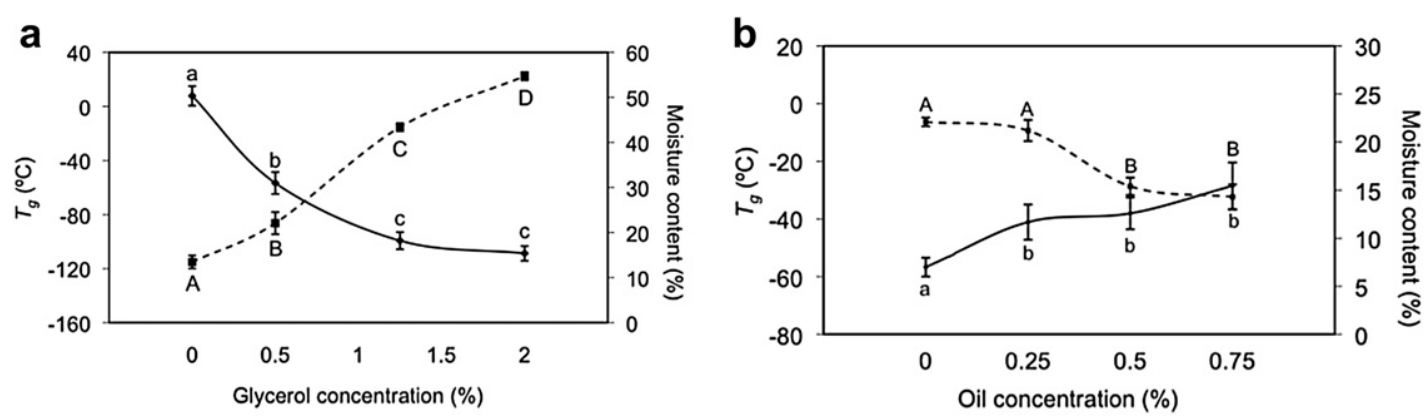

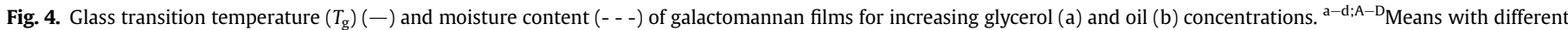
superscripts are significantly different $(p<0.05)$.

(Fabra, Talens, \& Chiralt, 2010; Mathew \& Dufresne, 2002). Also the increase of the moisture content in the film matrix when more hydrogen bonds are available can influence the intensification of films' crystallinity (Chen, Liu, Chen, Chen, \& Chang, 2008). The presence of oil does not provoke statistically significantly differences $(p>0.05)$ on the values of $\Delta H_{\mathrm{m}}$ and $T_{\mathrm{m}}$ for chitosan films (results not shown).

The melting peak was not observed for galactomannan films without glycerol and for films with oil concentrations above $0.5 \%$. The thermograms (results not shown) had a flat shape indicating an amorphous structure of these films (Mathew \& Dufresne, 2002; Yakimets et al., 2007). Fig. 5b shows that the increase of glycerol concentration leads to higher values of $\Delta H_{\mathrm{m}}$, that can be explained by the formation of crystalline domains, favored by the increase of the polymer mobility (lower $T_{\mathrm{g}}$ values) how was already explained elsewhere (Fabra et al., 2010; Mathew \& Dufresne, 2002; Sperling, 2006). Also, the increase of the moisture content in the film matrix when more hydrogen bonds are available can influence the crystallinity of the films (Chen et al., 2008). $T_{\mathrm{m}}$ values were not statistical significance influenced $(p>0.05)$ by the increase of glycerol concentration.

Thermogravimetric analysis determine the changes in weight of the films samples with the increase of the temperature. Tables 9 and 10 in the Supplementary data show the peak values of thermal events and the corresponding weight loss for each event, for chitosan and galactomannan films, respectively. Thermal analysis shows that chitosan films began the dehydration process at $60^{\circ} \mathrm{C}$ (results not shown), being stable below that temperature. They present at least three thermal events, however for samples with oil a fourth event was observed. Peak 1 is related with the evaporation process, a characteristic phenomenon of a polysaccharide with a hydrophilic nature. The differences in weight loss due to the presence of glycerol (peak 2) are also very marked, where an increase of the weight loss for higher glycerol concentrations is observed, related with the loss of chemisorbed water through hydrogen bonds and the elimination reaction of $\mathrm{NH}_{3}$ (Quijada-Garrido, Iglesias-González, MazónArechederra, \& Barrales-Rienda, 2007). Peak 3 (around $290{ }^{\circ} \mathrm{C}$ ) is related with the dehydration, depolymerization and pyrolytic decomposition of the polysaccharide backbone (Zohuriaan \& Shokrolahi, 2004). In films containing oil, where the plasticizer content is constant, the weight loss at peak 2 (related with the presence of glycerol) does not present statistically significant differences when the oil concentration was increased; however, there is an increase in the size of the peak associated with oil decomposition (peak 4), related with the aromatic structures present in corn oil with decomposition temperatures above $380^{\circ} \mathrm{C}$ (Pelissari et al., 2009).

Thermal analyses show that galactomannan films without glycerol are stable up to $40^{\circ} \mathrm{C}$, and when glycerol is added this stability increases up to $59^{\circ} \mathrm{C}$ (results not shown). Galactomannan films show at least three thermal events, the first being attributed to water evaporation, the second (around $200{ }^{\circ} \mathrm{C}$ ) attributed to the presence of glycerol, and the third related to polysaccharide decomposition (Zohuriaan \& Shokrolahi, 2004). As for chitosan films, for samples containing oil a fourth event was observed related with the aromatic structures present in corn oil with decomposition temperatures above $380^{\circ} \mathrm{C}$ (Pelissari et al., 2009). Peak events show that the increase of glycerol concentration leads to a more significant weight loss associated with two thermal events: water evaporation (peak 1), and chemisorbed water through the hydrogen bonds favored by the presence of glycerol (peak 2) (Quijada-Garrido et al., 2007). In films containing oil
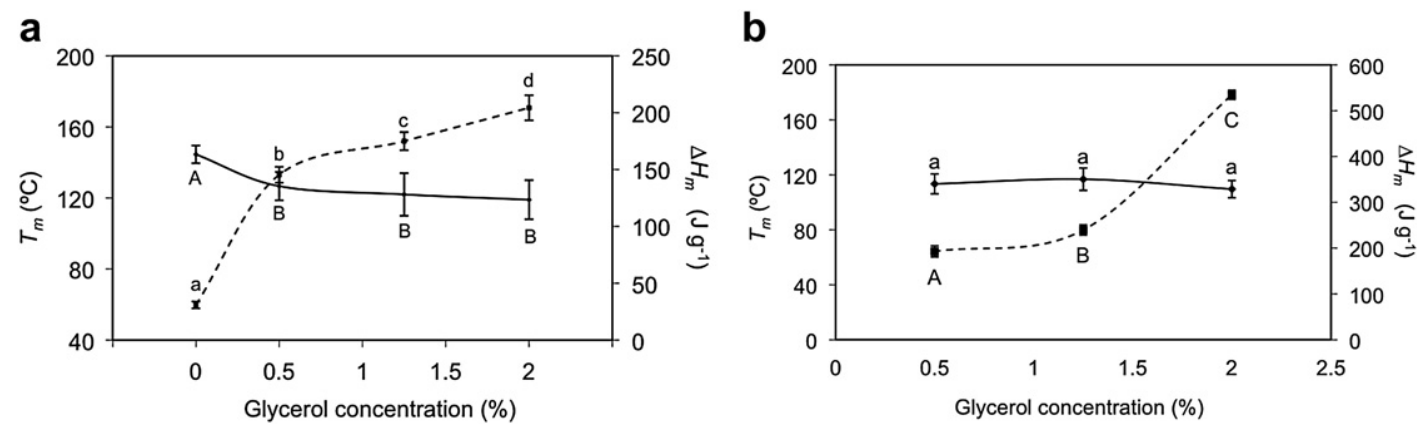

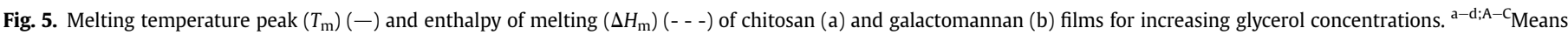
with different superscripts are significantly different $(p<0.05)$. 
a weight loss associated with oil decomposition is observed (peak 4); this loss was more substantial for samples with higher corn oil concentration.

\subsection{Water solubility}

The water solubility of edible films indicates their water resistance when applied, e.g., on water-rich foods such as peeled fruits. It is also related to the biodegradability of films when used as packaging materials (Gnanasambadam, Hettiarachchy, \& Coleman, 1997). Table 1 shows that water solubility of chitosan films increases for higher glycerol concentrations $(p<0.05)$. This is related with the hydrophilic behavior of glycerol and with the increase of $\mathrm{O}-\mathrm{H}$ bonds on chitosan films matrix with the increase of glycerol concentration, that are more available to interact with the water molecules, in agreement with FITR spectra analyses, values of moisture content and thermal events detected during TGA. On the other hand, the presence of oil and the increase of its concentration lead to a statistically significant decrease $(p<0.05)$ of the solubility. The decrease of the number of $\mathrm{O}-\mathrm{H}$ bonds, the appearance of aliphatic groups in the film when oil is added (as shown by FTIR results), and the corresponding increase of the hydrophobic portion of the film originated a less soluble material (Morillon, Debeaufort, Blond, Martine, \& Voilley, 2002).

Table 2 shows the solubility values of galactomannan films and indicates that both glycerol and oil influence their water solubility. The presence of oil and the increase of glycerol concentration show different effects. The increase of glycerol concentration leads to an increase $(p<0.05)$ of the solubility, motivated by the corresponding increase of the hydrophilicity of the film matrix. FTIR analyses showed an increase of $\mathrm{O}-\mathrm{H}$ bonds number with the increase of glycerol content; this means that glycerol fostered the interaction of the film matrix with water. Also the higher mobility of the matrix (lower $T_{\mathrm{g}}$ ) has a great influence in these results: in a system with improved mobility, water molecules enter more easily in the film matrix which results in an increase of its solubility.

Oil addition (from 0 to $0.25 \%$ ) does not cause a statistically significant difference $(p>0.05)$ in water solubility values. However, for oil concentrations of $0.75 \%$ a significant decrease of the solubility $(p<0.05)$ occurs. As explained before, for chitosan films, the hydrophobic character of oil changes the film structure leading to a less soluble film (i.e. decreases the number of $\mathrm{O}-\mathrm{H}$ bonds and the presence of an aliphatic groups). The results obtained are in agreement with the solubility values for other polysaccharide-based films (Casariego et al., 2009; Mehyar \& Han, 2004; Piermaria, Pinotti, Garcia, \& Abraham, 2009).

\subsection{Water vapor permeability (WVP)}

Water vapor permeability is the most extensively studied property of edible films. Table 1 shows that oil and glycerol have a distinct influence in WVP of chitosan films; while the WVP values increase for increasing glycerol concentrations, the presence of oil leads to a decrease of WVP. These results are in agreement with other works where the increase of plasticizer concentration has increased the values of WVP (Caner, Vergano, \& Wiles, 1998; Ziani et al., 2008). As already explained above, the increase of glycerol concentration leads to higher moisture contents of chitosan films. The plasticizer action increases the free volume and chain movements (lower $T_{\mathrm{g}}$ ), reducing the rigidity and increasing the molecular mobility of films, thus allowing a higher water vapor diffusion through their structure.

The presence of oil changes the properties of the films, decreasing the affinity for water. The decrease of the WVP values in chitosan films with the addition of oil can be explained by the diminution of the hydrophilic portion of the film (HernandezMunõz, López-Rubio, Del-Valle, Almenar, \& Gavara, 2004), that reduces its affinity for water molecules and consequently decreases WVP (Table 1). As already stated, higher glycerol concentrations lead to an increase of the moisture content in films, while for different oil concentrations the moisture content values do not present statistically significant differences $(p>0.05)$. So, if in the case of films without oil the glycerol effect was emphasized by the water influence (increase of moisture content), for films with oil this does not happen. The range of values obtained is in agreement with other reported works (Casariego et al., 2009; Wong, Gastineau, Gregorski, Tillin, \& Pavlath, 1992).

Galactomannan films present a similar behavior to chitosan films; however when $0.5 \%$ of glycerol is added to the galactomannan film no statistically significant difference $(p>0.05)$ of WVP values is observed (Table 2 ). The presence of the plasticizer decreases the occurrence of cracks and pores, improving the dispersion and flexibility of the film and thus decreasing gas permeability (Garcia, Martino, \& Zaritzky, 2000). Moreover, when glycerol concentration increases from $0.5 \%$ to $1.25 \%$ and then to $2.0 \%$ the WVP values increase significantly. Glycerol and its plasticizing effect increase the molecular mobility and decrease the rigidity of polysaccharide chains. In this case, the higher concentrations of plasticizer favor molecular mobility (decreasing $T_{\mathrm{g}}$ values) and the adsorption of water molecules, increasing WVP values (Diab et al., 2001). As observed for chitosan films, also for galactomannan films the increase of oil concentration leads to lower WVP values, however these differences are statistically significant $(p<0.05)$ only for oil concentrations higher than $0.25 \%$ (Table 2). The hydrophobic character of the oil blended with galactomannan polysaccharide changes the film properties decreasing their WVP.

\subsection{Tensile strength (TS) and elongation-at-break (EB)}

Tensile strength is the ability of a material to resist under tensile stress until it breaks and is one of the most important and widely

Table 1

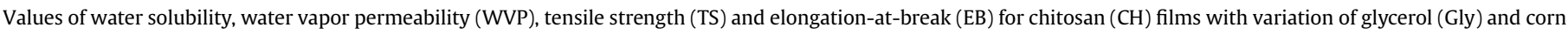
oil concentrations.

\begin{tabular}{|c|c|c|c|c|}
\hline Films & Solubility (\%) & $\begin{array}{l}\text { WVP } \times 10^{-11} \\
\left(\mathrm{~g} \mathrm{~m}^{-1} \mathrm{~s}^{-1} \mathrm{~Pa}^{-1}\right)\end{array}$ & TS (MPa) & EB (\%) \\
\hline $1.5 \%$ GT $-0.0 \%$ Gly & $42.25 \pm 0.33^{\mathrm{a}}$ & $5.07 \pm 0.23^{\mathrm{a}}$ & $21.45 \pm 2.82^{\mathrm{a}}$ & $16.18 \pm 3.53^{\mathrm{a}}$ \\
\hline $1.5 \%$ GT $-0.5 \%$ Gly & $51.86 \pm 0.16^{\mathrm{b}}$ & $8.61 \pm 0.38^{b}$ & $7.72 \pm 0.75^{\mathrm{b}}$ & $71.75 \pm 4.27^{\mathrm{b}}$ \\
\hline $1.5 \%$ GT $-1.25 \%$ Gly & $63.77 \pm 0.77^{c}$ & $10.16 \pm 0.18^{c}$ & $3.64 \pm 0.63^{c}$ & $86.18 \pm 4.88^{c}$ \\
\hline $1.5 \%$ GT $-2.0 \%$ Gly & $69.94 \pm 0.72^{\mathrm{d}}$ & $11.40 \pm 0.45^{d}$ & $1.17 \pm 0.06^{\mathrm{c}}$ & $99.52 \pm 2.84^{\mathrm{d}}$ \\
\hline $1.5 \%$ GT $-0.5 \%$ Gly $-0.25 \%$ oil & $48.98 \pm 1.07^{\mathrm{e}}$ & $8.28 \pm 0.33^{b}$ & $3.66 \pm 0.66^{c}$ & $65.08 \pm 2.72^{\mathrm{e}}$ \\
\hline $1.5 \%$ GT $-0.5 \%$ Gly $-0.5 \%$ oil & $45.20 \pm 0.95^{f}$ & $7.78 \pm 0.11^{\mathrm{b}}$ & $3.05 \pm 0.15^{c}$ & $63.01 \pm 3.34^{\mathrm{ef}}$ \\
\hline $1.5 \%$ GT $-0.5 \%$ Gly $-0.75 \%$ oil & $42.25 \pm 0.10^{\mathrm{a}}$ & $6.68 \pm 0.31^{\mathrm{e}}$ & $3.00 \pm 0.17^{c}$ & $56.01 \pm 5.77^{f}$ \\
\hline
\end{tabular}

Values reported are the means \pm standard deviations. ${ }^{a-f}$ Different letters in the same column indicate a statistically significant difference $(p<0.05)$. 
Table 2

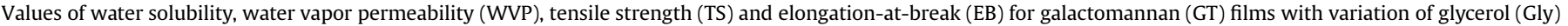
and corn oil concentrations.

\begin{tabular}{|c|c|c|c|c|}
\hline Films & Solubility (\%) & $\begin{array}{l}\text { WVP } \times 10^{11} \\
\left(\mathrm{~g} \mathrm{~m}^{-1} \mathrm{~s}^{-1} \mathrm{~Pa}^{-1}\right)\end{array}$ & TS (MPa) & EB (\%) \\
\hline $1.5 \%$ GT $-0.0 \%$ Gly & $22.00 \pm 0.70^{\mathrm{a}}$ & $8.38 \pm 0.57^{\mathrm{a}}$ & $18.55 \pm 4.43^{\mathrm{a}}$ & $3.77 \pm 0.09^{\mathrm{a}}$ \\
\hline $1.5 \%$ GT $-0.5 \%$ Gly & $44.35 \pm 0.47^{\text {bef }}$ & $7.87 \pm 0.13^{\mathrm{ac}}$ & $13.25 \pm 0.74^{\mathrm{ac}}$ & $11.94 \pm 0.47^{b}$ \\
\hline $1.5 \%$ GT $-1.25 \%$ Gly & $56.41 \pm 1.17^{c}$ & $12.32 \pm 0.17^{\mathrm{b}}$ & $2.58 \pm 0.30^{\mathrm{b}}$ & $34.22 \pm 1.10^{c}$ \\
\hline $1.5 \%$ GT-2.0\% Gly & $65.43 \pm 1.53^{\mathrm{d}}$ & $13.33 \pm 0.44^{\mathrm{b}}$ & $1.70 \pm 0.06^{\mathrm{b}}$ & $38.72 \pm 3.78^{c}$ \\
\hline $1.5 \%$ GT $-0.5 \%$ Gly $-0.25 \%$ oil & $48.39 \pm 3.87^{\mathrm{e}}$ & $7.80 \pm 0.34^{\mathrm{cd}}$ & $11.95 \pm 1.79^{\mathrm{cd}}$ & $14.35 \pm 1.18^{\mathrm{b}}$ \\
\hline $1.5 \%$ GT $-0.5 \%$ Gly $-0.5 \%$ oil & $41.84 \pm 1.12^{\mathrm{f}}$ & $7.14 \pm 0.35^{\text {de }}$ & $8.34 \pm 1.05^{\mathrm{d}}$ & $17.17 \pm 1.37^{\mathrm{d}}$ \\
\hline $1.5 \%$ GT $-0.5 \%$ Gly $-0.75 \%$ oil & $34.11 \pm 2.84^{\mathrm{g}}$ & $6.60 \pm 0.26^{\mathrm{e}}$ & $3.38 \pm 0.39^{e}$ & $21.27 \pm 4.40^{\mathrm{d}}$ \\
\hline
\end{tabular}

Values reported are the means \pm standard deviations. ${ }^{\mathrm{a}-\mathrm{e}}$ Different letters in the same column indicate a statistically significant difference $(p<0.05)$.

measured properties of materials used in structural applications. Elongation-at-break of a material is the percentage increase in length that occurs before it breaks under tension (Sperling, 2006).

The increase of plasticizer concentration exerts a great influence over TS values, and leads to a decrease of approximately $64 \%$ when $0.5 \%$ of glycerol was added to chitosan films (Table 1 ). For the same amount of added glycerol, EB values were 4.4-fold those of chitosan films without glycerol. Furthermore, when glycerol concentration increased from $0.5 \%$ to $2.0 \%$, this behavior was more evident with a decrease of TS values of approximately $85 \%$ and an increase of EB values of $39 \%$. Plasticizers interfere with chitosan chains: they decrease intermolecular forces, soften the rigidity of the film's structure and increase polymer mobility (in agreement with the $T_{\mathrm{g}}$ values observed), thus decreasing TS and increasing EB. The presence of glycerol leads to a ductile and flexible material. Furthermore, also the water content of the films when glycerol is added affects TS and EB, and accentuates the effect of the glycerol content (Ziani et al., 2008). These results are in agreement with those reported in the literature that show a decrease of TS values and an increase of EB values with the presence and increasing concentrations of plasticizer (Caner et al., 1998; Ziani et al., 2008).

Results in Table 1 show that the presence of oil influences both TS and EB values. Oil incorporation leads to a decrease of TS and EB values when compared with films without oil. Increasing oil concentrations from 0.5 to $0.75 \%$ did not have statistically significant influence $(p>0.05)$ on TS and EB values for chitosan films, suggesting that the chitosan matrix is not able to incorporate oil concentrations above $0.5 \%$. The oil presence leads to a less rigid film structure, being the structural discontinuities provoked by the oil incorporation possibly responsible for the decrease of their flexibility and their resistance to fracture (Sánchez-González, Vargas, González-Martínez, Chiralt, \& Cháfer, 2009).

Results in Table 2 show how glycerol concentrations affect TS values of galactomannan films. Galactomannan films without glycerol present a typical behavior of an unplasticized film: high values of TS and a great variability due to their non-homogeneous structure. It is important to note that galactomannan films without glycerol at room temperature are in the glass-rubber transition zone (Fig. 4a), which from a molecular point of view involves molecular motion and the beginning of reptation, leading to a non-uniform structure (Roos \& Karel, 1991; Sperling, 2006). The increase of glycerol concentration (from $0.5 \%$ to $2.0 \%$ ) had a statistically significant influence $(p<0.05)$ on the values of TS and EB. This increase lead to TS values $87 \%$ lower and values of EB 3.2-fold higher than those found in films without glycerol. As previously mentioned, plasticizers interfere with galactomannan chains where, by decreasing intermolecular forces, they reduce the rigidity of the film structure and increase the polymer mobility; this facilitates film elongation, in accordance with the $T_{\mathrm{g}}$ values obtained in the present work.

Table 2 shows that the presence of oil influences both TS and EB values for the galactomannan films. The oil incorporation leads to a decrease of TS and an increase of EB values when compared with the film without oil. This decrease only presents statistical significance $(p<0.05)$ for oil concentrations above $0.25 \%$. The results seem to indicate that oil acts as a plasticizer leading to a less rigid film structure, increasing its flexibility and decreasing its resistance to fracture. In the present work, the highest values of TS were obtained for the formulation containing $1.5 \%$ of galactomannan (18.6 MPa); and the highest value of EB was obtained for the film formulation containing $1.5 \%$ of galactomannan and $2.0 \%$ of glycerol (38.7\%). These results are in agreement with other reported results for galactomannan films (Martins, Cerqueira, Souza, Avides, \& Vicente, 2010; Mikkonen et al., 2007).

\subsection{Comparison between structure-properties relationships of chitosan and galactomannan films}

The study of the physicochemical properties of polysaccharide films shows how the presence of glycerol and/or corn oil can influence their structural reorganization. Water adsorption on the films' matrix for different glycerol and corn oil concentrations varies for both chitosan and galactomannan films, as shown by FTIR spectra, moisture content and thermal analyses results. The major differences between the used polysaccharides, from a structural point of view, lay in the substitution of the $\mathrm{O}-\mathrm{H}$ group by an $\mathrm{N}-\mathrm{H}$ function in the case of chitosan. This means that glycerol and oil will influence the structure of the films in a different way. While for the galactomannan the specific sorption sites for water are the $\mathrm{O}-\mathrm{H}$ groups, for chitosan those are $\mathrm{O}-\mathrm{H}$ and/or $\mathrm{NH}_{2}$ groups (Despond, Espuche, Cartier, \& Domard, 2005), thus changing their capacity to interact with water.

Chitosan and galactomannan films present a similar behavior when glycerol is added to the film. Glycerol leads to an increase of the moisture content; however, the obtained values for chitosan films are higher and statistically different $(p<0.05)$ from the values for galactomannan films. For films without glycerol moisture content values are 15.5 and $13.5 \%$ for chitosan and galactomannan, respectively; however, when glycerol is added to the film-forming solutions, the resulting chitosan films present a moisture content at least $12 \%$ higher than galactomannan films. This behavior can be explained by the presence of Tween 80 in all chitosan films. Tween 80 presents a hydrophilic-lipophilic balance (HLB) of 15 that indicates that the surfactant is readily soluble in water (Carneiroda-Cunha et al., 2009), increasing the ability of the chitosan matrix to adsorb water molecules. The water sorption occurs in two main steps: the water sorption on polymer sites and the water clustering surrounding the firstly sorbed water molecules (Fringant et al., 1996). The plasticizing effect of glycerol leads to a film matrix with more mobile regions with larger interchain distances, thus allowing the sorption of more water molecules to polysaccharide sites. Besides, glycerol's structure creates more hydroxyl bonds that promote the sorption of water molecules to the film.

Both polysaccharides are strongly water content dependent, however they present different behaviors when their thermal, transport and mechanical properties are compared. The major 
differences are observed in the glass transition temperature $\left(T_{\mathrm{g}}\right)$ water vapor permeability (WVP) and elongation-at-break (EB) values. $T_{\mathrm{g}}$ values for the both polysaccharides films show the wellknown plasticizing effect of glycerol, which results in a decrease of $T_{\mathrm{g}}$. However, they are in different states at room temperature. While chitosan films are in the glassy state, with $T_{\mathrm{g}}$ values higher than $20^{\circ} \mathrm{C}$ (with exception of chitosan films containing $2.0 \%$ of glycerol), galactomannan films are in the rubbery state (with exception of galactomannan films without glycerol, that present a brittle behavior). Galactomannan films without glycerol, at room temperature, are in the glass-rubber transition zone leading to a non-uniform structure (Roos \& Karel, 1991) meaning that glycerol is necessary for a correct processing of these films. TS values of galactomannan films without glycerol show an unplasticized film behavior with a great variability due to their non-homogeneous structure. However, for films containing glycerol $(0.5 \%)$ it is observed that TS values for galactomannan films are higher than those obtained for chitosan films. This behavior can be justified by the linear and neutral nature of the polymer chains of the galactomannan films, which can associate more easily through intermolecular hydrogen bonding (Nieto, 2009). Chitosan films present higher values for EB than galactomannan films, being this difference more evident for higher glycerol concentrations. The chitosan structure is more flexible due to the presence of $\mathrm{N}-\mathrm{H}$ bonds and this may be the reason for the observed behavior. Also, when oil is added chitosan and galactomannan films present distinct behaviors for EB values. While for chitosan the presence of oil leads to lower values of $E B$, for galactomannan films this presence increases the EB values. This behavior is possibly related with the emulsifying capacity of the chitosan film-forming solutions, which is higher than that of galactomannan film-forming solutions; when the films are cast, oil increases the structural discontinuities, decreasing film flexibility.

\section{Conclusion}

The presence of glycerol and corn oil leads to changes in the polysaccharide films structure, with the formation of new and/or the increase of the number of existing bonds in the films' structure. These bonds influence the water affinity of the films, and consequently change their properties. It has been indirectly shown how the structure of the films is influenced by the presence of plasticizer and/or oil through measurement of thermal properties (DSC and TGA) and chemical structure (FTIR), and such influence has been confirmed by the results for transport and mechanical properties, solubility and opacity. Moreover, chitosan and galactomannan films evaluated in this work provide water vapor permeability and elongation-at-break values in the range of e.g. cellophane films; they also show in some cases tensile strength values close to those reported for high-density polyethylene and low-density polyethylene (Han \& Gennadios, 2005), thus positioning them as possible alternatives to those synthetic materials.

\section{Acknowledgment}

Miguel A. Cerqueira gratefully acknowledge his fellowship (SFRH/BPD/72753/2010) to the Fundação para a Ciência e Tecnologia (FCT, Portugal), and Bartolomeu W. Sousa was recipient of a fellowship from the Coordenação de Aperfeiçoamento de Pessoal de Nível Superior (CAPES, Brazil).

\section{Appendix. Supplementary data}

Tables showing the results of FTIR and thermogravimetric analyses can be found, in the online version, at doi:10.1016/j. foodhyd.2011.07.007.

\section{References}

ASTM-D-882-91. (1991). Standard test methods for tensile properties of thin plastic sheeting. In ASTM. (Ed.), Annual book of ASTM standards, Philadelphia.

Bergo, P., \& Sobral, P. J. A. (2007). Effects of plasticizer on physical properties of pigskin gelatin films. Food Hydrocolloids, 21, 1285-1289.

Caner, C., Vergano, P. J., \& Wiles, J. L. (1998). Chitosan film mechanical and permeation properties as affected by acid, plasticizer and storage. Journal of Food Science, 63(6), 1049-1053.

Carneiro-da-Cunha, M. G., Cerqueira, M. A., Souza, B. W. S., Souza, M. P., Teixeira, J. A., \& Vicente, A. A. (2009). Physical properties of edible coatings and films made with a polysaccharide from Anacardium occidentale L. Journal of Food Engineering, 95(3), 379-385.

Casariego, A., Souza, B. W. S., Cerqueira, M. A., Cruz, L., Díaz, R., \& Vicente, A. A (2009). Chitosan/clay films' properties as affected by biopolymer and clay micro/nanoparticles' concentrations. Food Hydrocolloids, 23, 1895-1902.

Cerqueira, M. A., Lima, A. M., Souza, B. W. S., Teixeira, J. A., Moreira, R. A., \& Vicente, A. A. (2009). Functional polysaccharides as edible coatings for cheese. Journal of Agricultural and Food Chemistry, 57(4), 1456-1462.

Cerqueira, M. A., Pinheiro, A. C., Souza, B. W. S., Lima, A. M., Ribeiro, C., Miranda, C., et al. (2009). Extraction, purification and characterization of galactomannans from non-traditional sources. Carbohydrate Polymers, 75(3), 408-414.

Chen, J., Liu, C., Chen, Y., Chen, Y., \& Chang, P. R. (2008). Structural characterization and properties of starch/konjac glucomannan blen films. Carbohydrate Polymers, 74, 946-952.

Cuq, B., Gontard, N., Cuq, J. L., \& Guilber, S. (1996). Functional properties of myofibrillar protein based biopackaging as affected by film thickness. Journal of Food Science, 61(3), 580-584.

Despond, S., Espuche, E., Cartier, N., \& Domard, A. (2005). Hydration mechanism of polysaccharides: a comparative study. Journal of Polymer Science, Part B: Polymer Physics, 43, 48-58.

Diab, T., Biliaderis, C. G., Gerasopoulos, D., \& Sfakiotakis, E. (2001). Physicochemical properties and application of pullulan edible films and coatings in fruit preservation. Journal of the Science of Food and Agriculture, 81, 988-1000.

Dong, Y., Ruan, Y., Wang, H., Zhao, Y., \& Bi, D. (2004). Studies on glass transition temperature of chitosan with four techniques. Journal of Applied Polymer Science, 93, 1553-1558.

Ekthamasut, K., \& Akesowan, A. (2001). Effect of vegetable oils on physical characteristics of edible konjac film. AU Journal of Technology, 5(2).

Fabra, M. J., Talens, P., \& Chiralt, A. (2010). Water sorption isotherms and phase transitions of sodium caseinate-lipid films as affected by lipid interactions. Food Hydrocolloids, 24, 384-391.

Fountoulakis, M. S., \& Manios, T. (2009). Enhanced methane and hydrogen production from municipal solid waste and agro-industrial by-products codigested with crude glycerol. Bioresource Technology, 100, 3043-3047.

Fringant, C., Desbrières, J., Milas, M., Rinaudo, M., Joly, C., \& Esgoubes, M. (1996). Characterisation of sorbed water molecules on neutral and ionic polysaccharides. International Journal of Biological Macromolecules, 18, 281-286.

Garcia, M. A., Martino, M. N., \& Zaritzky, N. E. (2000). Lipid addition to improve barrier properties of edible starch-based films and coatings. Journal of Food Science, 65, 941-947.

Gnanasambadam, R., Hettiarachchy, N. S., \& Coleman, M. (1997). Mechanical and barrier properties of rice bran films. Journal of Food Science, 62(2), 395-398.

Gu, Y., \& Jérôme, F. (2010). Glycerol as a sustainable solvent for green chemistry. Green Chemistry, 12, 1127-1138.

Guillard, V., Broyart, B., Bonazzi, C., Guilbert, S., \& Gontard, N. (2003). Preventing moisture transfer in a composite food using edible films: experimental and mathematical study. Journal of Food Science, 68(7), 2267-2277.

Han, J. H., \& Gennadios, A. (2005). Edible films and coatings: a review. In J. H. Han (Ed.), Innovations in food packaging (pp. 239-259). New York: Academic Press.

Hernandez-Munõz, P., López-Rubio, A., Del-Valle, V., Almenar, E., \& Gavara, R. (2004). Mechanical and water barrier properties of glutenin films influenced by storage time. Journal of Agricultural and Food Chemistry, 52, 79-83.

Jamróz, M. E., Jarosz, M., Witowska-Jarosz, J., Bednarek, E., Tecza, W., Jamróz, M. H., et al. (2007). Mono-, di-, and tri-tert-butyl ethers of glycerol. A molecular spectroscopic study. Spectrochimica Acta, Part A, 67, 980-988.

Kök, M. S., Hill, S. E., \& Mitchell, J. R. (1999). Viscosity of galactomannans during high temperature processing: influence of degradation and solubilisation. Food Hydrocolloids, $13,535-542$.

Martins, J. T., Cerqueira, M. A., Souza, B. W. S., Avides, M. C., \& Vicente, A. A. (2010). Shelf life extension of ricotta cheese using coatings of galactomannans from nonconventional sources incorporating nisin against Listeria monocytogenes. Journal of Agricultural and Food Chemistry, 58(3), 1884-1891.

Mathew, A. P., \& Dufresne, A. (2002). Plasticized way maize starch: effect of polyols and relative humidity on material properties. Biomacromolecules, 3, 1101-1108.

McHugh, T. H., Avena-Bustillos, R. J., \& Krochta, J. M. (1993). Hydrophilic edible film: modified procedure for water vapor permeability and explanation of thickness effects. Journal of Food Science, 58, 899-903.

Mehyar, G. F., \& Han, J. H. (2004). Physical and mechanical properties of highamylose rice and pea starch films as affected by relative humidity and plasticizer. Journal of Food Science, 69(9), E449-E454.

Mikkonen, K. S., Rita, H., Helén, H., Talja, R. A., Hyvönen, L., \& Tenkanen, M. (2007), Effect of polysaccharide structure on mechanical and thermal properties of galactomannan-based films. Biomacromolecules, 8, 3198-3205. 
Morillon, V., Debeaufort, F., Blond, G., Martine, C., \& Voilley, A. (2002). Factors affecting the moisture permeability of lipid-based edible films: a review. Critical Reviews in Food Science and Nutrition, 42(1), 67-89.

Nelson, L. N., \& Cox, M. M. (2000). Lehninger principles of biochemistry. New York: Worth Publishers.

Nieto, M. B. (2009). Structure and function of polysaccharide gum-based edible films and coatings. In K. C. Huber, \& M. E. Embuscado (Eds.), Edible films and coatings for food applications (pp. 57-112). New York: Springer.

Olivas, G. I., \& Barbosa-Cánovas, G. V. (2008). Alginate-calcium films: water vapor permeability and mechanical properties as affected by plasticizer and relative humidity. LWT - Food Science and Technology, 41, 359-366.

Pelissari, F. M., Grossmann, M. V. E., Yamashita, F., \& Pineda, E. A. G. (2009). Antimicrobial, mechanical, and barrier properties of cassava starch-chitosan films incorporated with oregano essential oil. Journal of Agricultural and Food Chemistry, 57, 7499-7504.

Piermaria, J. A., Pinotti, A., Garcia, M. A., \& Abraham, A. G. (2009). Films based on kefiran, an exopolysaccharide obtained from kefir grain: development and characterization. Food Hydrocolloids, 23(3), 684-690.

Prashanth, K. V. H., \& Tharanathan, R. N. (2007). Chitin/chitosan modifications and their unlimited application - an overview. Trends in Food Science and Technology, 18, 117-131.

Quijada-Garrido, I., Iglesias-González, V., Mazón-Arechederra, J. M., \& BarralesRienda, J. M. (2007). The role played by the interactions of small molecules with chitosan and their transition temperatures. Glass-forming liquids: 1,2,3propantriol (glycerol). Carbohydrate Polymers, 68, 173-186.

Roos, Y., \& Karel, M. (1991). Plasticizing effect of water of thermal the behaviour and crystallization of amorphous food models. Journal of Food Science, 56(1), 38-43.

Sánchez-González, L., Vargas, M., González-Martínez, C., Chiralt, A., \& Cháfer, M. (2009). Characterization of edible films based on hydroxypropylmethylcellulose and tea tree essential oil. Food Hydrocolloids, 23(8), 2102-2109.

Santosa, F. X. B., \& Padua, G. W. (1999). Tensile properties and water absorption of zein sheets plasticized with oleic and linoleic acids. Journal of Agricultural and Food Chemistry, 47, 2070-2074.

Shahidi, F., Arachchi, J. K. V., \& Jeon, Y. J. (1999). Food applications of chitin and chitosan. Trends in Food Science and Technology, 10, 37-51.

Siracusa, V., Rocculi, P., Romani, S., \& Rosa, M. D. (2008). Biodegradable polymers for food packaging: a review. Trends in Food Science and Technology, 19, 634-643.

Sperling, L. H. (2006). Introduction to physical polymer science. New Jersey: John Wiley \& Sons, Inc
Srinivasa, P. C., Ramesh, M. N., \& Tharanathan, R. N. (2007). Effect of plasticizers and fatty acids on mechanical and permeability characteristics of chitosan films. Food Hydrocolloids, 21, 1113-1122.

Srivastava, M., \& Kapoor, V. P. (2005). Seed galactomannans: an overview. Chemistry E Biodiversity, 2, 295-317.

Suyatma, N. E., Tighzert, L., Copinet, A., \& Coma, V. (2005). Effects of hydrophilic plasticizers on mechanical, thermal, and surface properties of chitosan films. Journal of Agricultural and Food Chemistry, 53, 3950-3957.

Tanaka, M., Ishizaki, S., Suzuki, T., \& Takai, R. (2001). Water vapor permeability of edible films prepared from fish water soluble proteins as affected by lipid type. Journal of Tokyo University of Fisheries, 87, 31-37.

Üner, M., \& Altınkurt, T. (2004). Evaluation of honey locust (Gleditsia triacanthos Linn.) gum as sustaining material in tablet dosage forms. Il Farmaco, 59, 567-573.

Vargas, M., Albors, A., Chiralt, A., \& González-Martínez, C. (2009). Characterization of chitosan-oleic acid composite films. Food Hydrocolloids, 23(2), 536-547.

Vlachos, N., Skopelitis, Y., Psaroudaki, M., Konstantinidou, V., Chatzilazarou, A., \& Tegou, E. (2006). Applications of Fourier transform-infrared spectroscopy to edible oils. Analytica Chimica Acta, 573-574, 459-465.

Wong, D. W. S., Gastineau, F. A., Gregorski, K. S., Tillin, S. J., \& Pavlath, A. E. (1992) Chitosan lipid films: microstructure and surface energy. Journal of Agricultural and Food Chemistry, 40, 540-544.

Xu, Y. X., Kim, K. M., Hanna, M. A., \& Nag, D. (2005). Chitosan-starch composite film: preparation and characterization. Industrial Crops and Products, 21, 185-192.

Yakimets, I., Paes, S. S., Wellner, N., Smith, A. C., Wilson, R. H., \& Mitchell, J. R. (2007) Effect of water content on the structural reorganization and elastic properties of biopolymer films: a comparative study. Biomacromolecules, 8, 1710-1722.

Yi, H., Wu, L. Q., Bentley, W. E., Ghodssi, R., Rubloff, G. W., Culver, J. N., et al. (2005). Biofabrication with chitosan. Biomacromolecules, 6(6), 2881-2894.

Yuen, S. N., Choi, S. M., Phillips, D. L., \& Ma, C. Y. (2009). Raman and FTIR spectroscopy study of carboxymethylated non-starch polysaccharides. Food Chemistry, 114, 1091-1098.

Ziani, K., Oses, J., Coma, V., \& Maté, J. I. (2008). Effect of the presence of glycerol and Tween 20 on the chemical and physical properties of films based on chitosan with different degree of deacetylation. LWT - Food Science and Technology 41(10), 2159-2165.

Zohuriaan, M. J., \& Shokrolahi, F. (2004). Thermal studies on natural and modified gums. Polymer Testing, 23, 575-579. 